\title{
PRODUCCIÓN SOCIAL DEL HÁBITAT Y ORGANIZACIÓN DEL ESPACIO PÚBLICO Un enfoque etnográfico del proceso de territorialización en el asentamiento La Carbonilla
}

\author{
Lic. María Belén Garibotti \\ Instituto de Ciencias Antropológicas, Facultad de Filosofía y Letras, Universidad de Buenos Aires \\ Directora de la tesis de maestría en proceso: Dra. Ana Gretel Thomasz \\ mabelengaribotti@gmail.com
}

\section{RESUMEN}

Este trabajo se propone analizar los procesos de territorialización y de construcción de hábitat en el asentamiento informal La Carbonilla, ubicado en el barrio de La Paternal en la Ciudad Autónoma de Buenos Aires. Se analizan, desde un enfoque etnográfico, las estrategias y prácticas cotidianas de cuidado y mantenimiento de los espacios públicos. Se observa que los actores políticos del barrio -delegados y comisión directiva- y otros habitantes apelan cotidianamente a dispositivos materiales y simbólicos destinados al cuidado de los espacios de uso común dando cuenta de su influencia territorial a partir de su red de relaciones.

Palabras clave: territorio, habitar, espacio público, etnografía.

\begin{abstract}
The purpose of this work is to analyze the territorialization and habitat-building processes in the informal settlement La Carbonilla, located in the neighborhood of Paternal in the City of Buenos Aires. Daily strategies and practices of care and maintenance of public spaces are analyzed from an ethnographic perspective. It is observed that the political actors - delegates and board of directors- and other inhabitants, everyday appeal to material and symbolic devices for the care of the common use spaces, showing their territorial influence based on their network of relationships.
\end{abstract}

Key words: territory, inhabit, public space, ethnography. 


\section{INTRODUCCIÓN}

La Ciudad de Buenos Aires atraviesa desde las últimas cuatro décadas, un proceso de regresión de la distribución del espacio urbano residencial, producto del paradigma de la desregulación del mercado del suelo. Este fenómeno, conlleva como consecuencia la negación de acceso al suelo para los sectores de ingresos medios y bajos. El estado se ha venido desplazando de su rol como regulador del territorio para permitir que el capital en sus diversas formas se constituya como el principal ordenador del espacio urbano. Así, en tanto el capital inmobiliario y corporativo ha estado orientado a satisfacer la demanda de los sectores más solventes de la sociedad haciendo prevalecer una función mercantil de la vivienda, los sectores medios y bajos han permanecido excluidos del mercado formal del suelo urbano. Como contracara, se gestan de forma progresiva procesos masivos de autoconstrucción de vivienda y ciudad, llevados a cabo por los sectores populares conocidos como villas, asentamientos informales y Nuevos Asentamientos Urbanos.

Se puede observar, en el nivel de viviendas ociosas de la ciudad ${ }^{1}$, una demanda solvente que se encuentra saturada y otra demanda de los sectores más empobrecidos que no encuentran solución a su problema de vivienda y que producen hábitat por autoconstrucción en lugares con alto nivel de vulnerabilidad. Más aún, se percibe que algunos grupos sociales, cuyos jefes de familia podían tener, en años de crecimiento económico, trabajos de oficio con ingresos suficientes para la compra de materiales y construcción de vivienda, han permanecido excluidos del sistema de créditos por no poseer los requisitos formales para su acceso, por lo que han recurrido a comprar tierra y construir sus viviendas en asentamientos informales. En estos asentamientos, el estado local no intercede como ordenador del territorio dado que sus construcciones no figuran en los planos municipales. Es así que planteo aquí, para guiar el análisis, las siguientes preguntas: ¿cómo se lleva a cabo el ordenamiento del territorio en los asentamientos informales? ¿quiénes son los agentes que toman dicho rol? ¿cuáles son las lógicas que guían ese ordenamiento? Y por último, ¿cuáles son las estrategias que ponen en práctica dichos actores para delimitar el espacio público?

Por lo mismo, este trabajo se propone realizar un análisis situado de los procesos de territorialización y de construcción de hábitat en el asentamiento La Carbonilla, ubicado en la trama lindante a las vías del ferrocarril San Martín en el barrio de La Paternal en la Ciudad Autónoma de Buenos Aires (CABA). Partiendo de una indagación preliminar realizada en el marco del trabajo de campo, el análisis buscará poner el foco en las estrategias y prácticas cotidianas de cuidado y mantenimiento de los espacios públicos por parte de sus habitantes. Estas acciones están fundamentadas en el sostenimiento de las condiciones adecuadas para afrontar un eventual proceso de reurbanización e integración sociourbana a la trama formal de la ciudad, a partir de la presentación ante la legislatura de un proyecto de ley ${ }^{2}$ realizado en una mesa de trabajo participativa.

El objetivo del trabajo es por lo tanto analizar las estrategias y prácticas llevadas a cabo por los habitantes del barrio para construir acuerdos sobre los espacios de uso común y sostener dichos acuerdos en el tiempo. Se sostiene la hipótesis de que ante la ausencia de un organismo ordenador del territorio en las dinámicas cotidianas, el rol de los actores políticos del barrio -delegados y comisión directiva-, así como de otros habitantes, resulta clave en la elaboración de normas vinculadas al uso del suelo, instrumentos de regulación del espacio urbano y la organización y conservación de los espacios de uso común. A la vez que tienen un papel esencial en el control de los procesos de construcción de infraestructura y tendido de servicios por parte de organismos y empresas del estado.

Estos actores se ven en la necesidad de encontrar mecanismos que legitimen el ordenamiento del espacio actual y prevengan el avance de construcción de vivienda por parte de otros habitantes, de manera que los espacios de uso común queden cristalizados. Ante esto, apelan cotidianamente a dispositivos materiales y simbólicos y a estrategias de presión dando cuenta de su presencia territorial a partir de relaciones con diferentes actores: organismos y trabajadores del estado, vecinos, habitantes de otros asentamientos, trabajadores del ferrocarril ${ }^{3}$. A su vez, se sugiere que las estrategias utilizadas por los diferentes actores se encuentran vinculadas a la relación que tengan con el territorio a partir de sus trayectorias familiares y biográficas.

\footnotetext{
${ }^{1}$ La vivienda ociosa en la Ciudad de Buenos Aires alcanza el 23,9\% según el último Censo Nacional de Población y Hogares realizado en 2010.

${ }^{2}$ Conviene subrayar que son dos los proyectos presentados en la legislatura. Uno por la Defensoría del Pueblo de la Ciudad de Buenos Aires y otro por militantes del barrio.

${ }^{3}$ Así como también con otros actores con poder territorial que realizan actividades extralegales.
} 
En este sentido, vale decir, partimos de dos supuestos que guían el análisis: por un lado, que estas prácticas y estrategias son llevadas a cabo en el marco de la vida cotidiana; por otro lado, las mismas están atravesadas por formas diversas de habitar el espacio urbano -como se desarrollará más adelante-. De ahí que se toma la decisión teórico-metodológica de abordar el estudio de caso por medio del método etnográfico, el cual se propone abordar la relevancia de las narrativas locales a la vez que orientar el análisis a los procesos de la vida cotidiana. Para el análisis del caso, se abordará la forma en que los actores sociales, los habitantes de los asentamientos informales significan, valoran y simbolizan el espacio (Giglia, 2010). Asimismo, durante el trabajo de campo se han articulado técnicas de observación participante y análisis situado de la vida cotidiana, así como también realización de entrevistas ${ }^{4}$ semiestructuradas a los habitantes del barrio, a agentes trabajadores del estado que han participado en un plan de urbanización integral realizado en el año 2014 y militantes de organizaciones sociales presentes en el territorio.

\section{LA PRODUCCIÓN DE CIUDAD POR AUTOCONSTRUCCIÓN}

Para comenzar, quienes construyen ciudad son agentes sociales concretos y lo hacen por medio de acciones complejas que constituyen prácticas de incorporación de áreas nuevas al espacio urbano. Correa (1993) plantea una tipología para el análisis y distingue cinco grupos específicos: los propietarios de los medios de producción, los propietarios fundiarios, los promotores inmobiliarios, el estado y los grupos sociales excluidos. En sociedades altamente desiguales como las de las ciudades latinoamericanas, los grupos sociales excluidos desarrollan diferentes estrategias de acción para la ocupación del espacio urbano, por medio de la acción directa, pero también por medio de un trabajo persistente de demanda de derechos a las instituciones del estado.

En este escrito, se considera producción social del hábitat a una de las modalidades de autoproducción de vivienda por parte de los sectores populares, que se contrapone a la lógica mercantil ya que emerge de la demanda de la misma y combina las lógicas individual-familiar y colectivo-organizado (Rodríguez et al, 2007). En este sentido, el proceso de producción de ciudad en La Carbonilla se llevó a cabo a partir de una ocupación -y compra de tierras- discontinua en el tiempo, por parte de actores sociales diversos (cartoneros, habitantes de otro asentamiento cercano, habitantes de conventillos y migrantes), que tuvo su origen en el contexto de la crisis social y económica de fines de la década del noventa. En el lapso transcurrido desde sus orígenes a fines de la década del noventa hasta la actualidad, los habitantes del barrio se embarcaron en un proceso de transformación del espacio en el que fueron convirtiendo un predio de pastos altos abandonado en un espacio habitado y habitable, con redes de servicios públicos, calles, veredas, plazas y cancha de fútbol.

Así, los mecanismos de autoconstrucción de vivienda a los que se hace referencia en este escrito, son llevados a cabo por grupos familiares de bajos ingresos. Estas familias suelen erigir construcciones de buena calidad, dado que quienes trabajan en ellas, por lo general hombres del grupo, se desarrollan como albañiles de oficio en los edificios de la ciudad formal. Esta forma de producción involucra saberes difusos sobre la construcción, transferidos de padres a hijos (Giglia, 2010), como es el caso de los inmigrantes peruanos que por sus conocimientos nativos saben realizar construcciones en altura con estructuras antisísmicas.

La producción de la vivienda en el urbanismo popular es el resultado progresivo de un proceso (Rodríguez et al, 2007). En sí, la vivienda no crece de manera desordenada, su lógica de construcción puede estar vinculada a dos razones, el crecimiento de la familia o la necesidad de aumentar los ingresos del grupo construyendo una pieza para alquilar. Algunas veces estas razones se cruzan y las habitaciones que han sido construidas para alquilar pueden ser destinadas al uso de algún miembro del grupo familiar que ha migrado recientemente. De esta forma, si bien estos procesos de autoconstrucción surgen de la "lógica de la necesidad" (Herzer et al, 1994, citado en Rodríguez et al, 2007), en contraposición a la "lógica de la ganancia" (Ibíd.), esta forma de ciudad autoproducida ha generado submercados habitacionales, con precios muy cercanos a los del mercado formal, debido a que las exigencias de este último expulsa a las familias que no tienen trabajo en blanco o no poseen una vivienda como garantía para ingresar a alquilar.

Sin embargo, más allá de la construcción de la vivienda, la producción de ciudad envuelve también un conjunto de otras infraestructuras, soportes u equipamientos que puedan habilitar el despliegue de diversos usos y actividades (Rodríguez et al, 2007), lugares de encuentro y socialización, de circulación de autos y peatones, de reunión para los vecinos, de juegos para los niños y de festejo, entre otras. Como establece Giglia (2012),

\footnotetext{
${ }^{4}$ Es necesario aclarar que por motivos éticos, en los relatos extraídos de entrevistas, los nombres propios han sido cambiados con el objetivo de resguardar la identidad de los entrevistados y de sus referentes.
} 
el hábitat construido por el urbanismo popular, no solo conlleva lógicas sociales de producción distintas, sino que se encuentra asociado a culturas del habitar, formas de relación de los habitantes con el espacio diferentes. Así, los usos para los que son priorizados estos espacios están atravesados por procesos sociales, económicos, culturales y políticos, que son encarnados por actores en pugna. Las decisiones sobre donde se construye una capilla, cuál es el centro comunitario o cuántos centímetros va a tener una vereda, son disputadas y llevadas a cabo por los mismos habitantes en el marco de la vida cotidiana. Por lo mismo, ante la ausencia del estado como organismo ordenador del territorio, los habitantes de la ciudad informal tienen una implicación directa con la producción de ciudad.

De manera que nos referimos aquí a una forma de ocupación del espacio urbano y producción de ciudad llevada a cabo por los grupos excluidos por medio de diversas estrategias. En las mismas, las lógicas de construcción de vivienda tienen distintas razones: crecimiento familiar o destinar al arrendamiento para aumentar ingresos. A su vez, la construcción de infraestructura y espacios de uso común involucra lógicas y de producción y culturas del habitar distintas las de la ciudad formal.

\section{UN ENFOQUE ETNOGRÁFICO DEL TERRITORIO}

En función del propósito de este trabajo, corresponde aclarar que aquí se entiende territorialidad en términos de Sack, como el "intento individual o grupal de influenciar, afectar o controlar objetos, personas y relaciones delimitando y afirmando el control sobre un área geográfica" (1983:56). Como construcción social, y como espacio de relaciones (Raffestin, 1993), no es considerada estrictamente como una circunscripción de cosas en un espacio determinado, sino más bien como una relación social que puede ser afirmada de diferentes formas desde derechos de propiedad hasta la prohibición del uso de ciertas áreas (Sack, 1983). En este proceso, los actores a través de la acción sobre el espacio, construyen territorio por apropiación simbólica y material.

Estos grupos, precarizados en sus condiciones materiales de vida, se encuentran desterritorializados (Haesbaert, 2012), dado que el dominio del espacio que habitan no está jurídicamente en sus manos, sino de otros actores sociales o institucionales, con mayor capacidad de influencia territorial. En su aspecto jurídico, el dominio del territorio, está atravesado por diversas instituciones: el estado, las empresas ferroviarias, actores privados, entre otros. Como contraparte, se conforman territorialidades por formas de apropiación alternativas; esto es, construyen territorio en interacción con distintos actores de la sociedad civil y por medio de la lucha y la resistencia cotidiana (Sack, citado en Haesbaert, 2014). Estas formas de apropiación, no son solo simbólicas, esto es a partir del reconocimiento como miembros de una comunidad, los lazos de pertenencia y la formación de redes sociales; sino que también se objetivan a partir de los procesos de construcción de vivienda y de transformación de lo que antaño era caracterizado por sus mismos habitantes como "selva de pastos altos", "tierra de nadie" o el lugar de "los borrachos", en un barrio habitado. Pero también por la conformación y delimitación de espacios de uso común, calles, veredas y plazas; lugares que le otorgaron significación e identidad al barrio.

Desde el punto de vista etnográfico, el proceso de territorialización se lleva a cabo por medio de la acción de habitar, concepto que Giglia y Duhau (2008) definen como el proceso de poblamiento y de "domesticación del espacio". Esto es "una intervención paulatina y colectiva dirigida a la transformación de una parte de la naturaleza en territorio: un espacio organizado y significado colectivamente, mediante procesos socioculturales" (2008:329). Es así que esta relación entre los seres humanos y el espacio se constituye a partir de su interpretación, su utilización y su significación, reconocimiento de puntos de referencia y de uso colectivo, en tanto es un proceso que se gesta en las relaciones cotidianas y a partir de acuerdos sobre los usos del espacio y la formación colectiva de un orden local (Giglia, 2010). Para la conformación de dicho orden, se establece la necesidad de formular reglas colectivas, las cuales remiten a una cultura específica del espacio urbano.

La ciudad informal, desde una perspectiva antropológica, es un tipo de urbanización resultado de una serie de acciones individuales orientadas a la transformación de un espacio inhabitable en un espacio habitable (Giglia, 2010). Como curso de transformación del espacio, este proceso de domesticación comprende una serie de acciones, que en el caso de La Carbonilla empezaron, en un primer momento, por construir casillas con materiales recolectados de la calle, encontrar un resguardo para preparar los alimentos y conseguir agua, pasando por limpiar un basural, hasta el día de hoy cuando, en las asambleas de vecinos, se discute qué 
nombre ponerle a la calles y se solicita a los organismos del estado la culminación de las obras de asfalto. De modo que la vida cotidiana de los grupos populares se encuentra atravesada por los procesos políticos que los involucran a la vez que los tienen por protagonistas (Rodríguez y Di Virgilio, 2013).

Asimismo, entendemos la territorialidad como una relación social que puede ser abordada de distintas maneras. Aquí el habitar se constituye como una modalidad que comprende distintas acciones y supone la formación de un orden local. A su vez, y a los fines de este análisis, puede ser abordada desde un enfoque etnográfico. Por lo mismo, dentro de esta conformación de un orden local en el urbanismo popular, me propongo analizar el espacio público, dado que considero que es en esos espacios donde se condensan acuerdos, conflictos y consensos de los procesos de participación ciudadana de los habitantes.

\section{LA PRODUCCIÓN DEL ESPACIO PÚBLICO EN EL URBANISMO POPULAR}

Desde una concepción moderna, el espacio público, es resultado de la separación formal entre la propiedad privada urbana, ligada al derecho de edificar y definida en el catastro, y la propiedad pública (Borja y Muxi, 2003). Este implica reservar suelo libre de edificación destinado a la construcción de equipamientos colectivos, infraestructuras de movilidad y monumentos, entre otros elementos. Asimismo, tiene la capacidad de organizar un territorio para ser capaz de soportar usos y funciones diversas, a la vez que puede crear lugares. Es tanto un espacio de continuidad y diferenciación, como un ordenador del barrio y articulador de ciudad. A su vez, es un concepto jurídico, ya que se considera "un espacio sometido a una regulación específica por parte de la administración pública, propietaria o que posee la facultad del dominio sobre el suelo y que garantiza la accesibilidad a todos y fija las condiciones de utilización y de instalación de actividades" (Ibid.:27), mientras que en su dimensión sociocultural es el lugar de contacto entre las personas, de la sociabilidad propiamente urbana (Borja y Muxi, 2003; Duhau y Giglia, 2004). De ahí resulta que parte de la producción de espacio urbano se vincula con esta delimitación entre el espacio privado respecto del espacio colectivo de la calle (Giglia y Duhau, 2008).

Con todo, en las urbanizaciones populares, la delimitación de los espacios de uso público son el producto del proceso de lotificación, no su presupuesto (Giglia y Duhau, 2008). Esto es, los espacios públicos son demarcados una vez que las viviendas son construidas. A su vez, las lógicas de demarcación se llevan a cabo por medio de procesos diversos que pueden implicar la circulación de automóviles, el paso de peatones, de expansión de la vivienda, de venta de tierras y, a veces, de ocultamiento de actividades.

Ahora bien, en este escrito se acompaña el postulado de Giglia y Duhau (2008) quienes establecen que por más caótico que parezca el entorno de las urbanizaciones populares, se trata en efecto de "espacios reglamentados". Este proceso de transformación de un entorno natural hostil en un espacio habitable conlleva como resultado un "orden socio-espacial específico", e implica establecer ciertas reglas consensuadas colectivamente. Es así, que los habitantes del barrio saben bien qué se puede y qué no se puede hacer en y con las calles (ibíd.). Esto, en la ciudad informal porteña, se traduce fundamentalmente en el acuerdo de hasta dónde se puede construir vivienda, es decir dónde termina la propiedad privada y comienza el espacio público.

Como "ciudad del espacio negociado" (Ibid), posee una forma de producción que tiene como rasgos constitutivos la irregularidad jurídica en el parcelamiento y la propiedad del suelo. Asimismo, aquí la organización y características del espacio público son resultado de procesos de lotificación, de edificación de vivienda y de múltiples formas de apropiación y usufrutuo del espacio público para distintos fines. Ciertos usos del espacio público en los asentamientos informales, como hacer un asado o colocar una pileta pilopincho ${ }^{5}$ en la vereda, tienden a ser aceptados por los vecinos con frecuencia sin mucho conflicto. Sin embargo, otras prácticas regularmente aceptadas en este orden socioespacial, como la construcción de escaleras caracol por fuera de la vivienda, en La Carbonilla se encuentran prohibidas. Estas prácticas sociales relacionadas con el uso de los espacios y artefactos se cristalizan en un orden urbano (Duhau y Giglia, 2004) por medio de convenciones -normas y reglas- a veces tácitas, comprendidas por (casi) todos los habitantes, en las que intervienen creencias y perspectivas sobre las actividades.

En suma, la construcción del espacio público en el urbanismo popular es un proceso que se lleva a cabo después de la producción de vivienda e implica formas de usufrutuo atravesadas por lógicas diversas, a la vez que produce un "orden socioespacial específico" (Giglia y Duahu, 2008). Como señala la hipótesis que

\footnotetext{
${ }^{5}$ Pileta de lona
} 
guía este trabajo, dentro de este proceso, el rol que juegan algunos actores sociales con relativo poder territorial, es esencial para el sostenimiento de estas nomas convencionales, que alternan entre lo legítimo y lo ilegítimo.

\section{EL CASO DE LA CARBONILLA}

La Carbonilla es un asentamiento informal ubicado en la CABA., lindante a las vías del ferrocarril San Martín en la estación de Paternal. Sus terrenos pertenecen a la órbita del estado nacional, aunque sus habitantes sean ciudadanos de la CABA. Si bien, el último censo que se realizó fue en el año 2013, cuando vivían unas cuatrocientas familias, hoy según los trabajadores de la secretaría de villas de la Defensoría del Pueblo de la Ciudad, se estima que viven unas mil familias y cuatro mil personas aproximadamente.

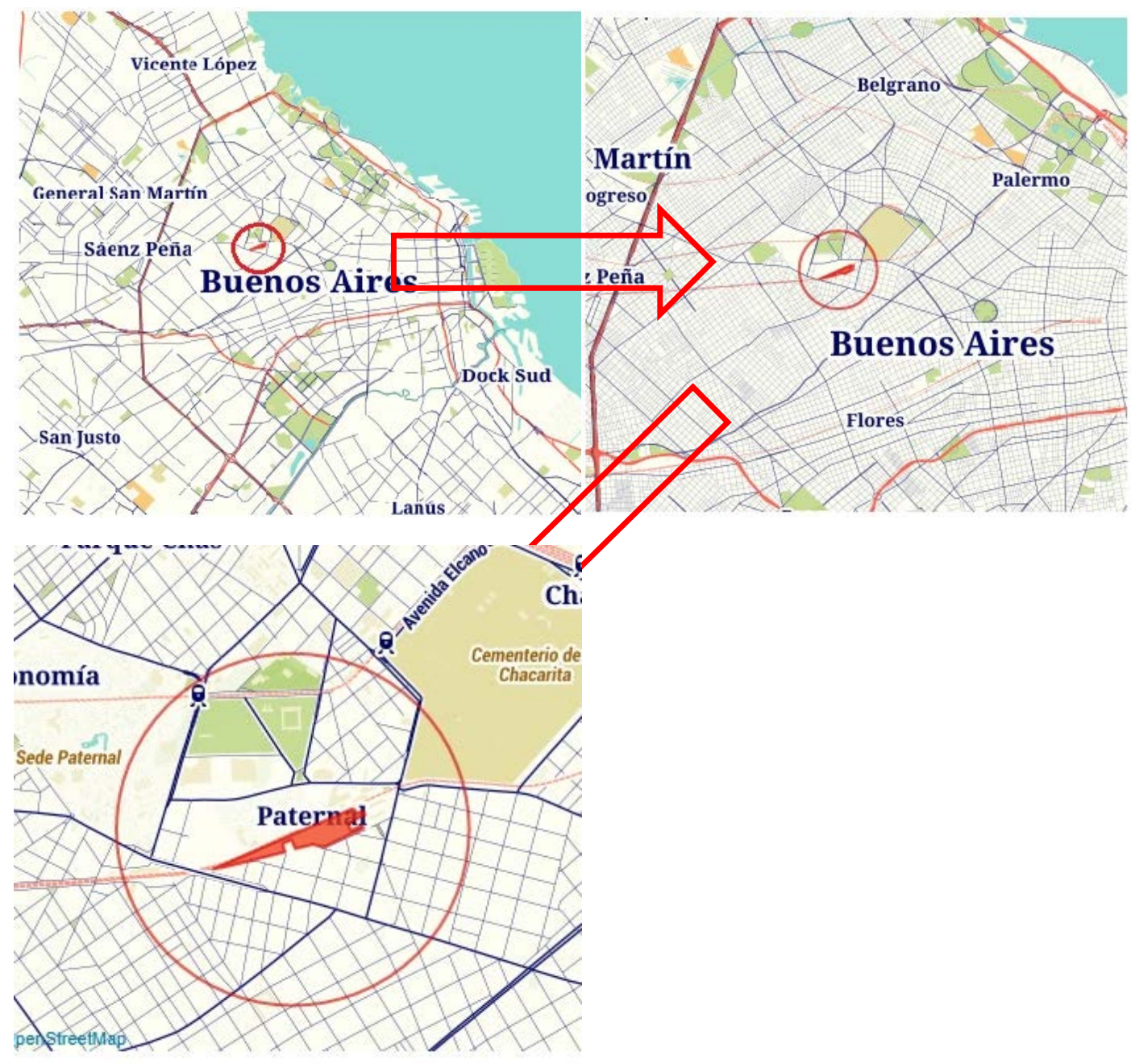

Ilustración 1: Mapas de localización de La Carbonilla en la Ciudad de Buenos Aires

Sus contornos limitan, por un lado, con las vías del tren y, por el otro, las calles Trelles, Añasco, Espinosa y en su parte más angosta alcanza hasta avenida San Martín. El polígono que conforma el barrio tiene un tejido 
heterogéneo, compartiendo la presencia de un comercio proveedor de materiales para la construcción y otro de venta de carbón y leña, conocido por los vecinos como "la carbonera", a partir de la cual se le da nombre al barrio. A su vez, adyacente a la estación del tren, se encuentran activos dos galpones que tienen uso logístico.

El barrio tiene un ordenamiento territorial particular, casi inalterado por la construcción de viviendas si se compara con lo que solía ser el predio de uso ferroviario. Conserva dos calles de un ancho suficiente para que puedan circular autos y camiones. Esto, en parte debido a la lógica de circulación de camiones que originalmente ingresaban a la carbonera por una entrada que quedaba en el centro del barrio, la cual hoy se encuentra cerrada por una pared. Hay dos manzanas marcadas por la presencia en el pasado de galpones a los que el tren entraba, por lo que muchos sectores tienen marcada la impronta de las vías del ferrocarril, en la elevación de algunas de sus veredas (a la altura de andenes), en la forma de sus manzanas (antiguos galpones) y en los rieles de ferrocarril que se pueden encontrar caminando por la calle.

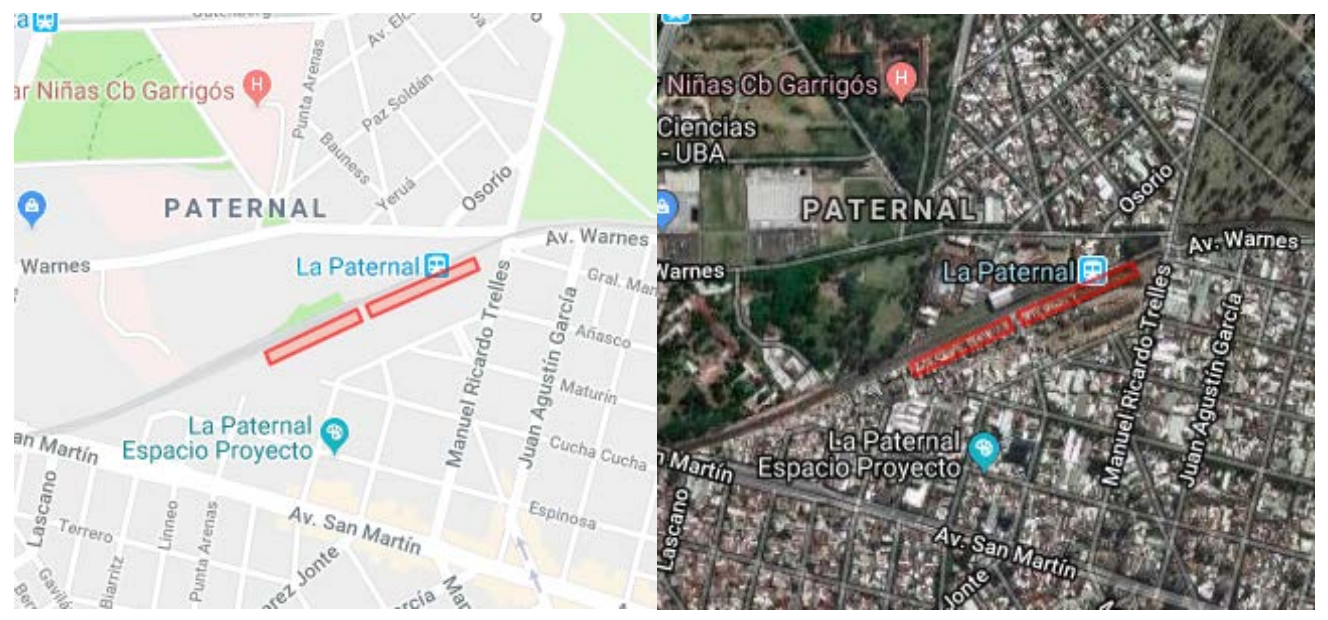

llustración 2: En rojo, el contorno de los ex-galpones ferroviarios

Si se hace referencia a la historia del barrio, se pueden mencionar cuatro hitos o etapas, que contribuirían a la caracterización de los actores que lo habitan, sus orígenes y sus actividades.

En primer lugar, originalmente vivían en el terreno algunas familias de trabajadores ferroviarios, que tienen permiso de habitar las tierras y que vieron crecer el asentamiento a su alrededor. De estas, hoy quedan al menos dos.

El segundo hito se da en el contexto de la crisis económica y social del 2001, cuando la actividad de los cartoneros comenzaba a crecer y formar parte del paisaje cotidiano de la ciudad. Estos trabajadores llegaban en el tren a la estación de Paternal desde los barrios de José C. Paz, San Miguel y alrededores, a recoger cartón y chatarra en la ciudad. Entonces empezaron a utilizar esas tierras vacías, en principio como un lugar operativo para el cartón, donde los fines de semana acopiarían lo recolectado para venderlo el lunes y volver a sus casas. Por lo mismo, esos días dormirían ahí. Con el paso del tiempo, se comenzarían a quedar durante la semana, por lo cual inscribirían a los hijos en las escuelas del barrio y de esa forma, generarían su arraigo.

Un tercer hito, se da en el año 2008 a partir del desalojo del asentamiento conocido como "la lechería" que estaba ubicado, del lado oeste del puente de San Martin, a metros de La Carbonilla. El desalojo de este edificio, bajo la gestión del recientemente electo jefe de gobierno Mauricio Macri, generó que algunas familias vayan a habitar esas tierras del otro lado del puente, lo que les permitía mantener el arraigo con el barrio.

Entonces, una cuarta etapa se da a partir de la valorización inmobiliaria de esas tierras, luego del año 2010. Algunas partes del predio que no eran utilizadas por los cartoneros comienzan a ser loteadas y vendidas, y el 
barrio a poblarse más. Este nuevo grupo es mayormente peruano y llega al barrio por medio de una lógica mercantil, comprando las tierras a precios no tan lejanos de los que se presentan en el mercado formal ${ }^{6}$. Debido a la organización de los habitantes del barrio y las organizaciones sociales, y en un contexto favorable de crecimiento económico, se iban trabajando mejoras en la infraestructura que creaban la idea de que la Carbonilla era uno de los asentamientos informales con mejor calidad de vida de la ciudad. Esto debido en parte, a la capacidad de compra de materiales de las familias para la construcción de las viviendas, pero también a la relación de los militantes barriales con los organismos del estado que les permitía articular el trabajo referido al tendido de la red servicios de agua y luz, que no son llevados a cabo por las empresas de servicios en estos barrios ya que sus calles no figuran en los mapas municipales. Es así, que en medio de este proceso de valorización, los cartoneros que ya tenían sus casas comenzaron a venderlas y a volverse a su barrio original en el Gran Buenos Aires (GBA).

Lejos de perseguir esencialismos sobre las características de cada grupo, podemos condensar lo dicho hasta aquí en que el barrio ha quedado conformado por diversos grupos: algunos vecinos "históricos" de origen ferroviario que vieron crecer una ciudad alrededor suyo; un grupo que se dedica a la recolección de cartón, al acopio y a la compra-venta de objetos y muebles en desuso, cuyo lugar de origen son algunos barrios del GBA y provincias del interior de país, suelen ser familias de muchas generaciones de vivir en asentamientos informales y pueden tener también sus casas en el GBA; otro grupo de origen popular proveniente también del barrio de La Paternal que desarrollan en algunos casos actividades de cartoneros, pero también de venta de comida o servicio de limpieza; y, por último, un grupo mayormente originario de distintas provincias de Perú de clase media con expectativas de ascenso social, que se consideran propietarios de esas tierras, y cuyas actividades son fundamentalmente de oficio (herreros, albañiles, cuidados de ancianos o costura), pero también comerciantes y profesionales como, por ejemplo, enfermeras.

Como se ha dicho, esta caracterización no intenta imponer esencialismos a cada grupo, sino más bien comprender, a partir de sus actividades cotidianas y sus orígenes, cuáles son sus motivaciones y sus intenciones, así como también cómo es la forma en la que habita -y produce- la ciudad cada grupo en función de esto.

En adelante, fue en el año 2013 que la justicia obligó al gobierno de C.A.B.A a reconocer a La Carbonilla como barrio. En el marco de la ley 148 de atención prioritaria a la problemática social y habitacional en las villas y núcleos habitacionales transitorios, se convocó a elecciones para representantes del barrio. A partir de entonces, el estatuto del barrio define que cada uno de los tres sectores, debe tener tres delegados y a su vez, una comisión directiva formada por cinco miembros, que tendrían como responsabilidad la articulación con el poder ejecutivo y legislativo para la continuación del trabajo "para el diagnóstico, propuesta, planificación y seguimiento de la ejecución de las políticas sociales habitacionales".

Más tarde, en 2014 en el marco del programa "100 barrios", se implementó un plan de reurbanización integral del barrio, con participación de la Secretaría Nacional de Acceso al Hábitat (SNAH), del Ministerio de Defensa y la ONG Secretaría de Enlace de Comunidades Autogestionarias (SEDECA). El desarrollo del plan quedó inconcluso a fines del año 2015 con el cambio de gestión del gobierno nacional. Sin embargo, en esa experiencia con los técnicos de la SNAH, se trabajó en un proyecto de definición de espacios públicos a partir de la elaboración de un plano y un reglamento urbano que establece las dimensiones de cada espacio, el cual sigue vigente con sus matices. Este plano, se constituyó como un dispositivo que funcione como guía para las futuras construcciones, a partir de un acuerdo entre los vecinos y la legitimidad de los delegados (Acero et al, 2016). Ese trabajo realizado en talleres y asambleas, y otros de años anteriores de jornadas militantes de construcción de cloacas y veredas, contribuyeron a un proceso de concientización con los vecinos y las organizaciones sobre la importancia de apuntar a los procesos de que desvirtúan el camino a la formalización. Esto es, verbigracia, evitando las construcciones en espacios públicos, las construcciones en altura excesivas y el aumento de la presencia de inquilinos.

\footnotetext{
${ }^{6}$ Este grupo utilizaba una lógica de compra de tipo cooperativa que llaman "pandero", juntan plata entre varias familias para comprar una casa, luego para comprar otra, hasta que cada familia del grupo tiene su casa.
} 


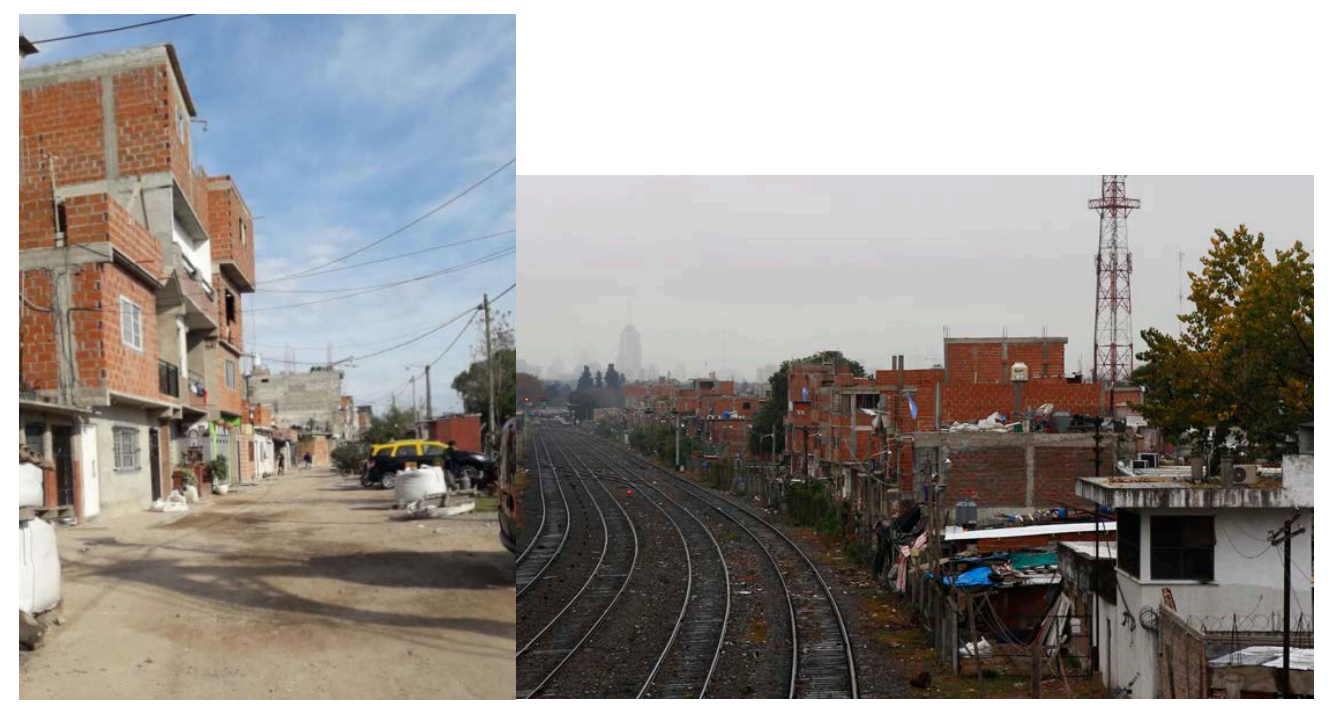

Ilustración 3: Calle del asentamiento. Ilustración4: El asentamiento visto desde el puente Fuente: Observatorio del Derecho a Fuente: Anccom la Ciudad

Entre los elementos de la forma urbana que condicionan el espacio público, espacios de referencia, que se pueden identificar hoy en el barrio, podemos mencionar los siguientes:

- El centro comunitario ubicado en el sector 2. Es la unidad básica de una de las organizaciones sociales. Debido a su historia y su institucionalización se fue conformando como el centro comunitario y su uso se encuentra abierto a las reuniones semanales de delegados y comisión directiva, así como también a las instituciones del estado.

- La "canchita". Está ubicada en el centro del barrio, por donde también circulan autos y camiones. Es el espacio articulador del barrio, geográfica y simbólicamente. En sus inicios era utilizado para hacer deportes. También allí se realizaban originalmente las reuniones y asambleas barriales. A su vez, es el lugar de encuentro durante las fechas festivas, como por ejemplo la procesión del Señor de los Milagros.

- Dos plazas con juegos ${ }^{7}$, una en el sector 2 ubicada en el mismo terreno que el centro comunitario y otra en el sector 3 , ambas enrejadas con el objetivo de que no entren los perros y de delimitar el espacio para que no avancen las construcciones sobre el mismo.

- Una capilla ubicada al costado de la canchita. Aunque está formada por un container, actualmente se encuentra en reformas, a partir de una negociación con el dueño del terreno lindante.

- Un playón utilizado como cancha ubicado en el sector 1. Es el espacio lindante a la estación del tren. Originalmente era un basural y su limpieza es considerada un hito importante en la historia del barrio, no solo por la habilitación para su nuevo uso como espacio deportivo, sino también porque un espacio de esas características cercano al paso del tren tendía a ser utilizado por personas ajenas al barrio para el consumo de paco, lo que traía situaciones de violencia para los habitantes del barrio.

- Dos calles paralelas y sus veredas. Una delimitada por el personal ferroviario con motivo de establecer un límite de seguridad. La segunda, marcada por el dueño de la carbonera, a partir de la necesidad de que los camiones puedan seguir entrando y saliendo. La presencia de veredas es un caso paradigmático, dado que no es frecuente en otros asentamientos informales de la ciudad. Estas fueron construidas por los vecinos quienes también pagaron los materiales, tienen aproximadamente 80 centímetros de ancho.

\footnotetext{
${ }^{7}$ Hay testimonios de que, a partir del trabajo de los agrimensores de la SNAH se había definido también como plaza un pequeño espacio ubicado en uno de los pasillos del sector dos que aún no estaba ocupado. Sin embargo, por motivos de seguridad no he tenido acceso aún, pero en entrevistas me han dicho vecinos que probablemente en ese pequeño espacio ya habrían avanzado con la construcción de viviendas.
} 


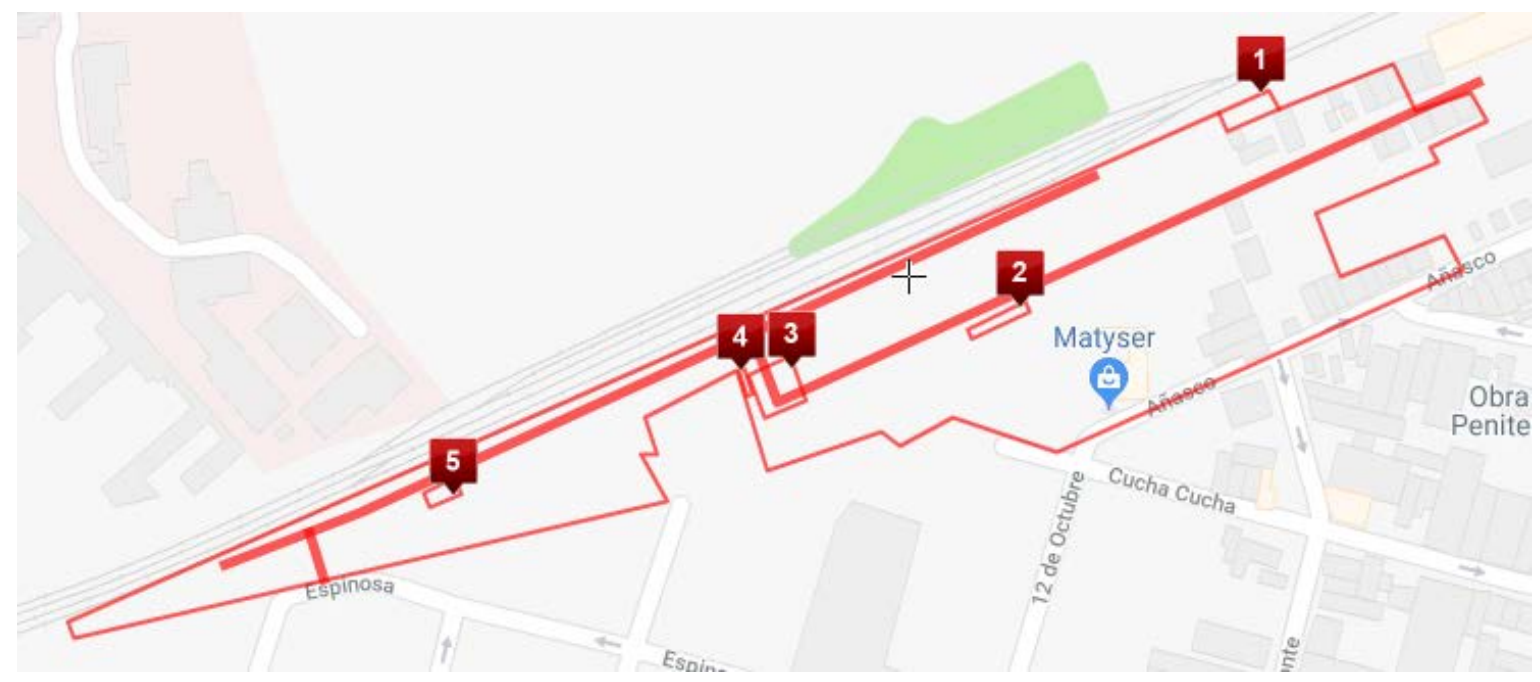

Ilustración 3: Mapa de espacios públicos del asentamiento

1: Playón deportivo

2: Plaza y centro comunitario

3: Espacio articulador del barrio: "la canchita"

4: Capilla

5: Plaza

: Calles

Es menester recalcar que si bien estos espacios fueron plasmados en el plano durante la ejecución del plan de urbanización de la SNAH, a partir del trabajo de los agrimensores, los militantes de organizaciones, los delegados y demás habitantes, en realidad estaban ya aceptados de hecho. Así, lo que se hizo en esa instancia fue simplemente volcarlos en un dispositivo que ayude a formalizar el ordenamiento territorial esas prácticas que se habían venido conformando en la cotidianeidad de la comunidad. Así, como establecen Duhau y Giglia (2004), el orden urbano en el urbanismo popular se encuentra sustentado en normas convencionales, más que en reglas formales, arreglos no escritos, en término de usos y costumbres.

A su vez, es necesario explicitar cuáles pueden ser las lógicas que fueron guiando este ordenamiento territorial. Como ya se mencionó, las calles se conformaron a partir de la necesidad del tránsito de camiones y las veredas fueron hechas en base a la demanda y el trabajo de los mismos vecinos, quienes también compraron los materiales para su realización. Por otra parte, la producción de vivienda pudo estar guiada por distintos factores, como ser la presión inmobiliaria, el crecimiento de la composición de la familia, pero también por los rumores de posibles procesos de urbanización que han ocasionado en diferentes períodos que más gente quiera vivir en el barrio.

Ese trabajo de formalización de los espacios públicos, apeló entonces a la conformación de elementos que legitimen los espacios que ya eran aceptados por la comunidad de vecinos. Hoy día, en los relatos cotidianos aparecen "el código", "el reglamento", "el plano", "la cuadrilla" como dispositivos simbólicos, aunque no aparezcan de forma tangible - de hecho, tampoco se da cuenta de una sanción ante su incumplimiento- a los que apelan los delegados para intervenir en un hecho conflictivo con algún vecino nuevo -o no tan nuevoante la posibilidad de que transgreda alguno de los acuerdos con la construcción de su vivienda.

En sí, este código prohíbe las construcciones de más de tres pisos de altura (aparte de la planta baja), las escaleras caracol por fuera de la vivienda y plantea la existencia de veredas de al menos 80 centímetros. Los tres ítems están fundamentalmente orientados a la prohibición del avance de las construcciones sobre el espacio público. También los delegados y miembros de la comisión insisten, ante la llegada de un vecino nuevo tanto cuando construye, como cuando llega un inquilino, en la necesidad de advertirle que no recurra a instalaciones ilegales de luz y de agua. Me afirman: "Cuando viene un vecino nuevo le decimos que espere la cuadrilla, que no se corte sólo", "no, usted nos tiene que llamar o avisarle a la comisión"8. Tanto la buena administración del servicio eléctrico, como la presencia de veredas y la ausencia de escaleras caracol afuera de las casas son elementos que conforman a la Carbonilla como un asentamiento preparado para afrontar un

${ }^{8}$ Fragmento de conversación mantenida con dos delegadas del barrio, 5/12/17. 
rápido proceso de reurbanización y los delegados velan por el mantenimiento de estas condiciones ante la presencia de planes de urbanización e integración socio-urbana en otros asentamientos y villas de la ciudad.

Como se estableció anteriormente, en este escrito se apoya el supuesto de que el hábitat popular, implica tanto lógicas sociales de producción distintas, como también diversas culturas del habitar (Giglia, 2012), formas de relación de los habitantes con el espacio diferentes, que están atravesadas por la conformación de la familia (que puede incluir padres, hermanos y otros miembros), por la relación con los vecinos, por las actividades que se desarrollen, por las migraciones de los grupos y por la antigüedad que tengan en el barrio, entre otros factores. Así, algunos actores logran imponer a los vecinos de su sector el cumplimiento de las normas en función de su relación con el territorio y de la apropiación que hayan desarrollado sobre él. Una entrevistada me cuenta un caso significativo sobre la construcción de veredas y el rol de una de las delegadas:

"Entrevistada: Otra cosa que me pareció divertida del espacio público es como la negociación de la vereda, que era una forma de que esté la vereda y que no avance la escalera caracol y que haya ahí como una línea. [...] Pero este particularmente, donde vive Griselda, está muy levantado. Están levantados porque el tren. Están a nivel del tren. Como le dimos tanta vuelta y definimos cómo tenía que ser y que se yo... Y Griselda es testaruda y es inteligente. Logró que todo el mundo respete esa veredita minúscula, que del otro lado estaba muy prolija, entonces era como... como está en frente. Y el primero que hizo como una barranca, una escalera para llegar hasta la calle como con más inclinación con una pendiente, se la hizo tirar abajo, no sé como pero lo logró...

\section{Entrevistadora: Griselda...}

Entrevistada: Griselda. Ella tiene como mucho territorio, pero la verdad que está desde siempre... Los hijos deben ser medio bravos. Hay alguna lógica ahí, no sé... donde lo logró. Cuestión que si mirás todo este borde son unos diseños muy raros de cómo ir bajando sin pasarse de la línea de la vereda... Digamos, toda una cuadra de unos tipos que se volvieron locos porque no tenían que pasar esta línea para que exista la vereda". (Fragmento de entrevista con Sabrina, ex-trabajadora de la SNAH y militante del barrio)

El desarrollo de la territorialidad, esto es la influencia y el control sobre un espacio geográfico (Sack, 1983), por parte de estos actores se llevó a cabo aquí a través de la acción, que implicó la apropiación concreta por medio del trabajo realizado sobre él. El territorio así se fue conformando como un espacio de relaciones (Raffestin, 1993). Es así que existen algunos actores con mayor poder territorial, ya sea porque son vecinos históricos, por su militancia o porque pueden imponerse por la fuerza, que pueden llegar a transgredir estas normas cuestionando los dispositivos. Sin embargo, la intervención de estos actores no suele ser negativa, ya que en casos como los que se presentan pueden movilizar la organización del espacio, como es el caso de una de las delegadas que logró movilizar la limpieza de uno de los pasillos más angostos del barrio:

"Las cosas que hicimos, que estuvo bueno eso. Pensar este pasillo, siempre fue como el peor. Digamos, esto era un quilombo y se reordenó solo. Con la organización vecinal que ahí dio Mónica, ídola. El pasillo siempre más enquilombado y ella motorizó eso... Después... con (la construcción de) la cloaca tuvieron que levantar todo el rancherío que tenían, lo levantaron, hicieron vereda, hicieron calle. La banco." (Fragmento de entrevista con Paula, militante del barrio)

La presencia territorial parece ser clave en lo que respecta al cuidado del espacio, no solo para hacer cumplir "el código" si no también para trabajar en el control cotidiano de las obras de infraestructura y tendido de redes de servicios que realice cualquiera de los organismos del estado en el territorio. Como expresa el siguiente fragmento, los habitantes del barrio se encuentran involucrados en esos procesos de trabajo y saben que pueden opinar teniendo conciencia de que es un espacio en permanente construcción:

"iAhora quieren 1,20 de vereda!, ¿Para qué querés tanta vereda? Eso sumado a los 4 metros de la calle no va a alcanzar. Pero nosotros estuvimos mal, porque cuando ellos (los peruanos) llegaron y empezaron a construir tendríamos que haberles dicho que no avancen tanto" (Graciela, vecina del barrio, fragmento de entrevista, 25/1/18)

Otra de las funciones más importantes de los delegados y miembros de la comisión directiva es a través de su relación con los organismos del estado. En tanto que hasta el 2015, la relación de los militantes de las organizaciones con trabajadores de los organismos del estado se constituía como una estrategia para mitigar la espera de los mecanismos burocráticos, hoy día su relación se da a través de mecanismos más bien administrativos. Esto es la presentación de notas con pedidos específicos a diferentes oficinas, como ser Autopistas Urbanas S.A.; Instituto de Vivienda de la Ciudad, a la Unidad de Gestión e Intervención Social (UGIS), a la Secretaría de Hábitat, al Ministerio de Ambiente y Espacio Público. A su vez, en la presentación 
ante reuniones de la UGIS en las que a veces participan vecinos que no son delegados. De igual forma, estas actividades se distribuyen entre distintos actores del barrio y se llevan a cabo en el marco de las acciones cotidianas, como en las visitas a vecinos del barrio para tomar mates o en una jornada de ida al microcentro por motivos personales y familiares, que se intercalan con trámites. Si bien en algunos casos, estos vecinos han realizado cursos de formación orientados a los procesos de urbanización, el conocimiento del funcionamiento de los organismos burocráticos se ha ido desarrollando a través de la práctica continua y en charlas con habitantes de otros barrios, guiados por el convencimiento de que a los procesos de intervención de espacio público en los barrios es necesario acompañarlos para controlar su desarrollo.

Resumiendo, el espacio público se observa aquí como el resultado de un proceso de construcción en base a las prácticas y actividades cotidianas de los habitantes del barrio, por ejemplo, quienes se dedican a la recolección de cartón y objetos en desuso, priorizan los espacios disponibles para su función logística, mientras que quienes se dedican a la construcción aprovechan sus días libres para realizar mejoras en sus casas. Esto es, cada grupo tiene una particular relación con el espacio que habitan. Así, la conformación del plano se presenta como el resultado y la cristalización de las normas convencionales productos de los usos y costumbres de los actores.

\section{CONCLUSIÓN}

Citando a la antropóloga francesa Catherine Neveu, el trabajo de campo etnográfico no pretende construir una coyuntura local como objeto de estudio, sino más bien procura abordar empíricamente procesos sociales localizados. En este sentido, se procuró dar cuenta de una forma de producir ciudad desde la perspectiva actores en el marco de un proceso de producción social del hábitat, la cual puede interpelar a las representaciones y supuestos que se asumen desde las políticas públicas destinadas a estos grupos interviniendo por medio de un organismo o no de otro.

Doreen Massey expresó que la imbricación entre espacio y poder es la clave para el cambio político, "el espacio está imbuido de poder y el poder siempre tiene una espacialidad" (2009:19). Es así que considero que los asentamientos populares son espacios de construcción activa del poder popular y los espacios públicos, lugares que cristalizan largos procesos de participación ciudadana. Aquí, las formas participación política, la participación y el control sobre los procesos de trabajo, como la toma de decisiones o la realización de un trámite para solicitar acelerar el fin de una obra, se encuentran imbricados en la práctica y en las relaciones sociales cotidianas de los habitantes.

Retomando las preguntas planteadas al inicio de este escrito, el ordenamiento del territorio se lleva a cabo a partir de la cristalización de prácticas cotidianas por parte de sus habitantes, pero también de otros actores, como ser el tránsito de camiones o las actividades de los trabajadores del ferrocarril. En la Carbonilla, como en otros asentamientos populares de la ciudad de Buenos Aires, prevalecen diversas representaciones sobre como habitar la ciudad. Las perspectivas de los inquilinos, de los propietarios, de los habitantes de casas ferroviarias, de los cartoneros que articulan el uso del espacio para la vivienda con su función logística y de los habitantes que hacen uso de sus casas como comedores comunitarios, intervienen activamente todos los días en la construcción de ciudad.

Como se fue delineando en las últimas páginas, y convalidando la hipótesis que guió este trabajo, algunos actores con mayor participación política, tienen mayor poder territorial. Ellos apelan a instrumentos materiales y simbólicos consensuados por la comunidad. Así, "el código", "el plano", "el reglamento", "la cuadrilla" se presentan como categorías sociales (Guber, 2004) que no solo dan cuenta del sentido que le otorgan al espacio público y al mantenimiento del mismo, sino que también contribuyen a la negociación de estos espacios que en lo cotidiano son disputados por diversas lógicas. Sin embargo, también pueden apelar a otras estrategias para hacer cumplir esas normas, como el conocimiento de los vecinos, el aprovechamiento de los lazos de parentesco (por ejemplo, pedir ayuda a los hijos para enfrentar a los vecinos), su relación con otros militantes y el trabajo realizado en el barrio (por ejemplo, participación en la construcción de veredas). Así, la territorialidad que desarrollan se da a partir no solo de la influencia y el control sobre el espacio colectivo sino también, por medio de la construcción de redes, con vecinos, familiares, militantes, habitantes de otros asentamientos y trabajadores del estado. 


\section{BIBLIOGRAFÍA}

ACERO, J., AGUILAR, D., ENCINA TUTUY, N., MARTíN, T. y PINILLOS, L. (2016) "Cartografías y métodos para la construcción social del hábitat" Ponencia presentada en VIII Jornadas sobre etnografia y metodos cualitativos. . IDES / CAS Buenos Aires, 10-12 de agosto.

BORJA, J y MUXI, Z. (2003) El espacio público: ciudad y ciudadanía. Barcelona. Electa.

CORREA, R. L. (1993) O Espaço Urbano. Sao Paulo: Editora Atica.

DI VIRGILIO, M. M. y RODRÍGUEZ, M. C. (Comps.) (2013) Producción social del hábitat. Abordajes conceptuales, prácticas de investigación y experiencias en las principales ciudades del Cono Sur. Buenos Aires: Café de las Ciudades.

DUHAU, E. y GIGLIA, A. (2004) Espacio público y nuevas centralidades. Dimensión local y urbanidad en las colonias populares de la ciudad de México. Papeles de población, 41: 167-194.

- (2004) Conflictos por el espacio y el orden urbano. Estudios demográficos y urbanos, 19: 257-288.

- (2008) Las reglas del desorden. Habitar la metrópoli. Siglo XXI-UAM.

GIGLIA, A. (2010) Producir y habitar la ciudad informal. Reflexiones desde la antropología. En: ALFIE, M., AZUARA, I., BUENO, C., PEREZ NEGRETE, M. Y TAMAYO, S. (coords.), Sistema mundial y nuevas geografías, Universidad Autónoma Metropolitana, Unviersidad Iberoamericana y México: Editorial Porrúa.

- (2012) El habitar y la cultura: perspectivas teóricas y de investigación. Universidad Autónoma de México: Iztapalapa.

GUBER, R. (2004 [1991]). El Salvaje Metropolitano. Buenos Aires: Paidós.

HAESBAERT, R. (2014) Viver no limite: território e multi/transterritorialidade em tempos de in-segurança e contenção. Rio de Janeiro: Bertrand Brasil.

- (Julio, 2012). Del mito de la desterritorialización a la multirterritorialidad. Conferencia dictada en el Instituto de Investigaciones Sociales, Universidad Nacional Autónoma de México.

HERZER, H., DI VIRGILIO, M. M. y RODRÍGUEZ, M. C. (2008), ¿Informalidad o informalidades? Hábitat popular e informalidades urbanas en áreas urbanas consolidadas, Pampa Revista Interuniversitaria de Estudios Territoriales, núm. 4, pp. 85-112.

MASSEY, D. (2009) Concepts of Space and Power in Theory and in Political Practices. Documents d'Análisi Geogràfico, 55.

RAFFESTIN, C. (1993) Por uma geografia do poder. San Pablo, Ática.

RODRÍGUEZ, M. C., DI VIRGILIO, M. M., PROCUPEZ, V., VIO, M., OSTUNI, F., MENDOZA, M., y MORALES, B. (2007). Producción social del hábitat y políticas en el Área Metropolitana de Buenos Aires: Historia con desencuentros. Universidad de Buenos Aires. Instituto de Investigaciones Gino Germani, Buenos Aires.

SACK, R. (1983) Human Territoriality. Cambridge: Cambridge Univ. Press.

\section{Fuentes electrónicas}

Ley 148. Villas y Núcleos Habitacionales Transitorios:

http://www2.cedom.gob.ar/es/legislacion/normas/leyes/ley148.html (Consultada: 20/11/2017) 